\title{
Relevance of the IES/NSF Protocol to Identification of Evidence-Based Practices
}

\author{
Barbara R. Schirmer \\ Walden University \\ Alison S. Lockman \\ Walden University \\ Todd N. Schirmer \\ Saybrook University
}

\begin{abstract}
The Institute of Education Sciences (IES) and the National Science Foundation (NSF) issued common guidelines that provide a protocol by which the use of particular methodological designs in a line of research inquiry provides evidence for each successive step in the process of bringing any given instructional intervention into practice. Our purpose was to determine if research on two widely used literacy instruction approaches has been conducted at each methodological stage in the IES/NSF protocol and is relevant to identifying the approach as an evidence-based practice. We applied the IES/NSF pipeline-of-evidence guidelines to assess whether practices touted as having a research base for effectiveness have emerged from an accumulation of empirical evidence and identification of conceptual or theoretical frameworks. In mapping the six steps of the IES/NSF protocol onto the shared book reading and reciprocal teaching studies that had met What Works Clearinghouse evidence standards, we found that only reciprocal teaching involved research at each stage in the protocol and only reciprocal teaching was identified as an evidence-based instructional approach by the What Works Clearinghouse. Our results indicate that the IES/NSF pipeline-of-evidence protocol offers a productive approach to identifying evidence-based practices. The different trajectories of research on reciprocal teaching and shared book reading indicates that research at each stage in the protocol is important to the development of an instructional approach that ultimately demonstrates effectiveness in improving student learning outcomes.
\end{abstract}

Keywords: research methodology, evidence-based practices, instructional interventions

\section{Introduction}

In the United States, the national debate on the meaning and value of scientific research has involved a spectrum of views ranging from those of public policymakers who describe educational research as being in a dismal state to scholars who describe educational research as a complex set of methodologies necessary to match to complex research questions. Given concerns about the quality of research in education and questions about what constitutes evidence for informing instructional practice, several preeminent professional organizations developed standards for quality research including the American Educational Research Association (2006), American Association of Colleges for Teacher Education (2006), Council for Exceptional Children (2005, 2014), and Division 16 of the American Psychological Association and Society for the Study of School Psychology (2003).

These efforts were intended to identify methodologies that provide trustworthy findings to be used for distinguishing between evidence-based practices and the notion of best practices. Best practices 
emerged from individual perspectives on the value of a particular instructional practice based on personal experience, predisposition, and interpretations of a particular body of literature. There has never been consensus around criteria for what constitutes evidence for best practices (Schirmer \& Williams, 2008). Alternatively, evidence-based practices are intended to emerge from verifiable, scientific evidence for effectiveness in improving learning outcomes (Cook, Smith, \& Tankersley, 2012; Detrich, Keyworth, \& States, 2008). The research community may argue about what kinds of research are scientific but the intent is to seek agreement on criteria rather than to continue relying on disparate notions on the nature of scientific evidence. Establishing practices as evidence-based should not only provide teachers and other stakeholders with a more objective and complete indication of which practices can be considered evidence-based but may also begin to change perceptions regarding the trustworthiness and importance of educational research.

Despite considerable discussion in the literature, at conferences and meetings, and in online venues about evidence-based practices, no consensus has emerged about what constitutes sufficient evidence to identify a practice as research-based, with proposed algorithms involving dissimilar configurations of quantities, qualities, and types of research studies (e.g., Cooper, 2010; Council for Exceptional Children, 2014; Gersten et al., 2005; Kazdin, 2011; What Works Clearinghouse [WWC], 2017). Cook et al. (2012) posited that on the one hand, it is encouraging to see that "evidence-based education is gaining a foothold in the collective consciousness of educators," but on the other hand, "the seeming ubiquity of the term may be its death knell" as it becomes "synonymous with best practices and therefore fails to connote anything of consequence" (p. 521).

In August of 2013, the Institute of Education Sciences (IES; U.S. Department of Education) and the National Science Foundation (NSF) issued common guidelines for education research and development. Their purpose was "to identify the spectrum of study types that contribute to development and testing of interventions and strategies, and to specify expectations for the contributions of each type of study" (IES \& NSF, 2013, p. 8). The report describes relevant educational research as forming a pipeline of evidence that contributes to the accumulation of empirical evidence and development of theoretical models. Unlike previous efforts to determine which studies provide sufficient evidence to identify an educational practice as research based, the IES/NSF guidelines provide a protocol by which the use of particular methodological designs in a line of research inquiry provides evidence for each successive step in the process of bringing any given instructional intervention into practice. The IES/NSF guidelines seem particularly important given that these federal agencies distribute millions of dollars in grants annually to support research that meets their defined criteria of quality research and promising evidence for practice.

The term line of research inquiry connotes building a body of knowledge from study to study. Researchers always begin a new investigation by reviewing the prior research on the topic to situate a new study within a context of what is already known to move knowledge about the topic forward. The term also implies that knowledge derived from research proceeds from observing and describing phenomena, to uncovering the links between phenomena, and then to influencing phenomena to generate particular outcomes. The principle of converging evidence has been proposed as a means for drawing on the findings from studies employing different designs to conclude whether a practice is research-based. To this end, we mapped the six steps of the IES/NSF protocol onto the shared book reading and reciprocal teaching studies that had met What Works Clearinghouse (WWC) evidence standards. Our purpose was to determine if research on two widely used literacy instruction approaches has been conducted at each methodological stage in the IES/NSF protocol and is relevant to identifying these instructional approaches as evidence-based practices. 


\section{Method}

\section{Mode of Inquiry}

To test the protocol, we examined the empirical evidence for two popular interventions used for literacy instruction and mapped this evidence to the steps in the IES/NSF pipeline of evidence. Our mode of inquiry involved a qualitative analysis of the published research on each intervention to determine first, whether the methodological designs in this body of prior research match with each step in the protocol and second, whether evaluation by WWC of the research evidence for each intervention is related to a history of studies that move from one step to the next in the protocol.

We selected reciprocal teaching and shared book reading for two reasons. One is that both are recommended as research-based in many popular literacy textbooks (e.g., Gunning, 2016; Reutzel \& Cooter, 2016; Vacca et al., 2015). The second is because WWC had conducted intervention reports on reciprocal teaching (U.S. Department of Education, IES, WWC, 2013) and shared book reading (U.S. Department of Education, IES, WWC, 2015).

Reciprocal teaching is a model developed by Palincsar and Brown (1984) for enhancing reading comprehension through dialogue that encourage collaborative problem solving between teachers and students. Four activities form the basis of the dialogue between the teacher and students in a reciprocal teaching lesson. In the first step, the students predict what will happen in the upcoming passage. After the students read the passage, the teacher, who initially is the classroom teacher and later is one of the students taking over the role of teacher, generates questions about the passage. The questions lead to clarifications that are needed by any of the students. This third step involves monitoring comprehension and using repair strategies when comprehension has broken down. In the fourth step, the teacher summarizes the passage and asks for modifications to the summary, or the teacher asks one of the students to summarize the passage. The clarification step is revisited when the students differ about the main ideas and salient details included in the summary. The lesson ends with the students' making predictions about the passage to be read the next day. Initially, the teacher leads the dialogue but gradually the teacher transfers responsibility for initiating and sustaining dialogue to the students while continuing to provide feedback and coach the students.

Shared book reading is a model for early literacy instruction with roots in Holdaway's (1979) belief that reading aloud to young children is not sufficient; children need to be able to see the print, be guided and supported in experiencing the print, and participate in the reading experience. In this model, the teacher sits in front of the children with a book large enough for the children to see the print, typically referred to as a big book, and join in the reading. The teacher introduces the story and leads a discussion about the cover, title, and illustrations. The children are encouraged to predict the story line, after which the teacher reads the story aloud. The teacher engages the children in a discussion of the story and then the children are asked to retell the story; either one child retells it to the group or the children take turns retelling it with the group or to a peer. The teacher rereads the book several times and each time the teacher increases the children's attention to the written words by inviting them to read and by pointing out print and language patterns.

\section{Data Sources}

We began with the WWC intervention reports on reciprocal teaching (U.S. Department of Education, IES, WWC, 2013) and shared book reading (U.S. Department of Education, IES, WWC, 2015). We selected WWC because it has addressed the need for education decision makers to have a credible source of information about the quality of research on educational interventions since its establishment as an initiative of the U.S. Department of Education's IES in 2002. WWC 
disseminates its findings in a variety of formats including summaries of findings in intervention reports and educator practice guides (WWC, n.d.).

The intervention reports provided a listing of studies that met the WWC criteria for inclusion in the review (see WWC, n.d., for a full explanation of the WWC review protocol). We used these lists as the data source for studies on the two interventions of interest. Our analysis focused on the segments of the studies in which the authors discussed the line of research inquiry that led to their current study. We then examined the primary sources cited for the theoretical or conceptual framework that grounded their study, studies on the phenomena that led to the development of the intervention, investigations of the intervention's efficacy under highly controlled conditions, and investigations of the intervention's effectiveness when delivered by practitioners in actual instructional settings. We then mapped our findings to the IES/NSF pipeline-of-evidence protocol.

The IES/NSF pipeline-of-evidence protocol consists of the following categories:

Research Type 1: Foundational involves studies that provide foundational knowledge of teaching and learning, develop and refine theory, and examine phenomena in the absence of a direct link to educational outcomes.

Research Type 2: Early stage/exploratory involves studies that examine the connections or relationships among constructs that may result in the development of a new intervention.

Research Type 3: Design and development involves studies that draw on theory and empirical evidence in designing an intervention and testing individual components.

Research Type 4: Efficacy involves studies that test the intervention under ideal circumstances.

Research Type 5: Effectiveness involves studies that test the intervention under typical circumstances or conditions of routine practice.

Research Type 6: Scale-up involves studies that test the intervention under typical circumstances but in a wide range of contexts and populations.

\section{Results}

We found that the research on reciprocal teaching identifies Vygotsky's (1978) theory of the zone of proximal development as the foundational knowledge (Research Type 1) for scaffolding instruction, the core of the instructional model. Research on the relationships between comprehension and the metacognitive skills of making predictions, seeking clarification, generating questions, and summarizing were discussed as early stage or exploratory (Research Type 2) to developing the model. Palincsar and Brown $(1984,1986,1988)$ incorporated these early stage relationships identified in prior research in designing, developing, and testing the components of reciprocal teaching (Research Type 3). We found numerous studies in which the model was taught by trained experimenters (e.g., Alfassi, 1998; Gilroy \& Moore, 1988; Klingner \& Vaughn, 1996; Lysynchuk, Pressley, \& Vye, 1990; Marston, Deno, Kim, \& Diment, 1995) to investigate efficacy (Research Type 4) and studies with regular classroom teachers using the model in their own classes (e.g., Kelly, Moore, \& Tuck, 1994; Marks et al., 1993; Westera \& Moore, 1995) to investigate effectiveness (Research Type 5). We also found studies with populations other than the original population of adolescent students and in online delivery (e.g., Fuchs et al., 2001; Huang \& Yang, 2015; Mandel, Osana, \& Venkatesh, 2013) that illustrate how the intervention was investigated in a wide range of contexts and populations (Research Type 6). A summary of these results is provided in Table 1. 
Table 1. Summary of Results

\begin{tabular}{|c|c|c|}
\hline $\begin{array}{l}\text { IES/NSF Research } \\
\text { Type }\end{array}$ & Reciprocal Teaching & Shared Book Reading \\
\hline $\begin{array}{l}\text { Research Type 1: } \\
\text { Foundational }\end{array}$ & $\begin{array}{l}\text { Vygotsky's theory of the zone of } \\
\text { proximal development underlies } \\
\text { the importance of scaffolding in } \\
\text { instruction }\end{array}$ & $\begin{array}{l}\text { Concept of emergent literacy, } \\
\text { which is that children learn about } \\
\text { literacy from birth until } \\
\text { conventional reading and writing } \\
\text { instruction }\end{array}$ \\
\hline $\begin{array}{l}\text { Research Type } 2 \text { : } \\
\text { Early stage/exploratory }\end{array}$ & $\begin{array}{l}\text { Research on relationships between } \\
\text { comprehension and the } \\
\text { metacognitive skills of making } \\
\text { predictions, seeking clarification, } \\
\text { generating questions, and } \\
\text { summarizing }\end{array}$ & $\begin{array}{l}\text { Home literacy activities of } \\
\text { preschool children vary by } \\
\text { socioeconomic status and may } \\
\text { account for differences in literacy } \\
\text { achievement }\end{array}$ \\
\hline $\begin{array}{l}\text { Research Type } 3: \\
\text { Design and } \\
\text { development }\end{array}$ & $\begin{array}{l}\text { Palincsar \& Brown (1984) } \\
\text { developed and investigated } \\
\text { reciprocal teaching as an approach } \\
\text { incorporating the early stage } \\
\text { relationships }\end{array}$ & $\begin{array}{l}\text { Shared book reading was not } \\
\text { developed by any one researcher or } \\
\text { group of researchers though } \\
\text { Holdaway (1979) is credited for the } \\
\text { origins of the approach }\end{array}$ \\
\hline $\begin{array}{l}\text { Research Type 4: } \\
\text { Efficacy }\end{array}$ & $\begin{array}{l}\text { Researchers investigated } \\
\text { reciprocal teaching in regular } \\
\text { education settings but the } \\
\text { intervention was conducted by } \\
\text { trained experimenters (e.g., } \\
\text { Alfassi, 1998; Gilroy \& Moore, } \\
\text { 1988; Klingner \& Vaughn, 1996; } \\
\text { Lysynchuk et al., 1990; Marston et } \\
\text { al., 1995) }\end{array}$ & $\begin{array}{l}\text { No studies were found that } \\
\text { examined shared book reading } \\
\text { under ideal circumstances (WWC, } \\
2010,2015 \text { ) }\end{array}$ \\
\hline $\begin{array}{l}\text { Research Type 5: } \\
\text { Effectiveness }\end{array}$ & $\begin{array}{l}\text { Researchers investigated } \\
\text { reciprocal teaching conducted by } \\
\text { regular classroom teachers in their } \\
\text { own classes (e.g., Kelly et al., 1994; } \\
\text { Marks et al., 1993; Westera \& } \\
\text { Moore, 1995) }\end{array}$ & $\begin{array}{l}\text { Researchers investigated shared } \\
\text { book reading conducted by regular } \\
\text { classroom teachers in their own } \\
\text { classes (e.g., Box \& Aldridge, 1993; } \\
\text { Justice et al., 2010) and by parents } \\
\text { at home (e.g., Bojczyk et al., 2016; } \\
\text { Han \& Neuharth-Pritchett, 2015) }\end{array}$ \\
\hline $\begin{array}{l}\text { Research Type 6: } \\
\text { Scale-up }\end{array}$ & $\begin{array}{l}\text { Researchers investigated } \\
\text { reciprocal teaching with } \\
\text { populations other than the original } \\
\text { population of adolescent students } \\
\text { and in online delivery (e.g., Fuchs } \\
\text { et al., 2001; Mandel et al., 2013) }\end{array}$ & $\begin{array}{l}\text { Researchers investigated shared } \\
\text { book reading with populations } \\
\text { other than the original population } \\
\text { of preschool children at-risk for } \\
\text { later reading difficulties (e.g., } \\
\text { Piasta et al., 2012; Pollard- } \\
\text { Durodola et al., 2011) }\end{array}$ \\
\hline
\end{tabular}

The research on shared book reading identifies the concept of emergent literacy as foundational to the intervention (Research Type 1), which posits that children learn about literacy from birth until conventional reading and writing instruction. Research demonstrating that home literacy activities of preschool children vary by socioeconomic status and may account for differences in literacy achievement appeared in the research as early stage or exploratory in developing the model (Research Type 2). We found that shared book reading was not developed by any one researcher or group of researchers through design and development studies (Research Type 3), though Holdaway (1979) is credited for the origins of the approach. We were unable to identify studies of shared book reading in the ideal-type circumstances that would demonstrate efficacy (Research Type 4) but numerous studies with regular classroom teachers using the model in their own classes (e.g., Box \& 
Aldridge, 1993; Justice, McGinty, Piasta, Kaderavek, \& Fan, 2010) and by parents at home (e.g., Bojczyk, Davis, \& Rana, 2016; Han \& Neuharth-Pritchett, 2015) to investigate effectiveness (Research Type 5). We also found studies with preschool children at-risk for later reading difficulties (e.g., Piasta, Justice, McGinty, \& Kaderavek, 2012; Pollard-Durodola et al., 2011) that illustrate studies that tested the intervention under typical circumstances beyond the original population of preschool children. These results are summarized in Table 1.

\section{Discussion and Conclusion}

We began this study with the question of whether the IES/NSF pipeline-of-evidence protocol offers a productive approach to identifying evidence-based practices because it takes into account the role of methodological designs in lines of research inquiry. Instead of examining quality indicators for individual methodologies that lead to characterizing a practice as evidence-based (e.g., Council for Exceptional Children, 2014), we applied the IES/NSF pipeline-of-evidence guidelines to assess whether practices touted as having a research base for effectiveness have emerged from an accumulation of empirical evidence and identification of conceptual or theoretical frameworks. In the case of reciprocal teaching, WWC reported medium to large evidence for gains in comprehension in the research. We found that empirical evidence was manifest at each stage of the pipeline, which indicates a tentative connection between evidence of effectiveness and a line of inquiry that includes research that builds from the development of theory to studies examining the connections or relationships among constructs that result in the development of a new intervention, which is then tested in clinical and practical settings. In the case of shared book reading, foundational, early stage, design/development, and efficacy research was absent; WWC found mixed effects for gains in comprehension and language development and no discernible effects on alphabetics and reading achievement. That is, research on shared book reading followed an uneven path of methodological designs according to the IES/NSF protocol and is not identified as an evidence-based practice according to the WWC evaluation.

In mapping the six steps of the IES/NSF protocol onto the shared book reading and reciprocal teaching studies that had met WWC evidence standards, we found that only reciprocal teaching involved research at each stage in the protocol and only reciprocal teaching was identified as an evidence-based instructional approach by WWC. Our purpose had been to determine if research on two widely used literacy instruction approaches has been conducted at each methodological stage in the IES/NSF protocol and is relevant to identifying the approach as an evidence-based practice. Our results indicate that the IES/NSF pipeline-of-evidence protocol offers a potentially productive approach to identifying evidence-based practices. The different trajectories of research on reciprocal teaching and shared book reading indicates that research at each stage in the protocol is important to the development of an instructional approach that ultimately demonstrates effectiveness in improving student learning outcomes, as in the case of reciprocal teaching, or not recognized as evidence-based, as in the case of shared book reading.

Our approach to examining lines of research on interventions offers an alternative to identifying evidence-based practices through a narrow lens of experimental studies or even more narrowly, random assignment experiments as the prior approaches such as Council for Exceptional Children would suggest. The narrower lens has led to what Malouf and Taymans (2016) found is "a dim picture of the evidence base on education interventions" (p. 454) and suggested that the evidence base would be strengthened by incorporating a wider range of methodologies that are better suited to research in school settings, such as single case and other nonrandomized designs.

Our conclusions from analysis of the lines of research on reciprocal teaching and shared book reading are consonant with Malouf and Taymans' that policymakers and federal agencies should widen the net of methodologies that constitute a framework for elements needed to make predictions of 
effectiveness for any given intervention. By funding studies that employ methodologies at each stage in the protocol, the likelihood will be greater that experimental studies of instructional interventions at the latter stages of the protocol will show evidence of effectiveness in improving student learning outcomes because earlier research led to the development of the intervention through studies that provided foundational knowledge, examined relationships among constructs, and drew on theory and prior evidence in designing the intervention and testing individual components.

\section{References}

Alfassi, M. (1998). Reading for meaning: The efficacy of reciprocal teaching in fostering reading comprehension in high school students in remedial reading classes. American Educational Research Journal, 35, 309-332. doi:10.2307/1163426

American Association of Colleges for Teacher Education. (2006). Research guidelines for schools, colleges, and departments of teacher education. Washington, DC: Author.

American Educational Research Association. (2006). Standards for reporting on empirical social science research in AERA publications. Educational Researcher, 35, 33-40. doi:10.3102/0013189x035006033

Bojczyk, K. E., Davis, A. E., \& Rana, V. (2016). Mother-child interaction quality in shared book reading: Relation to child vocabulary and readiness to read. Early Childhood Research Quarterly, 36, 404-414. doi:10.1016/j.ecresq.2016.01.006

Box, J. A., \& Aldridge, J. (1993). Shared reading experiences and Head Start children's concepts about print and story structure. Perceptual and Motor Skills, 77, 929-930. doi:10.2466/pms.1993.77.3.929

Cook, B. G., Smith, G. J., \& Tankersley, M. (2012). Evidence-based practices in education. In K. R. Harris, S. Graham, \& T. Urdan (Eds.), APA educational psychology handbook, Volume 1: Theories, constructs, and critical issues (pp. 493-525). Washington, DC: American Psychological Association.

Cooper, H. (2010). Research synthesis and meta-analysis: A step-by-step approach (4th ed.). Los Angeles, CA: Sage.

Council for Exceptional Children. (2005). Criteria for evidence-based practice in special education [Special issue]. Exceptional Children, 75.

Council for Exceptional Children. (2014). Council for Exceptional Children: Standards for evidencebased practices in special education. Retrieved from https://www.cec.sped.org/ /media/Images/Standards/CEC\%20EBP\%20Standards\%20cover/C ECs\%20Evidence\%20Based\%20Practice\%20Standards.pdf

Detrich, R., Keyworth, R., \& States, J. (2008). Advances in evidence-based education (Vol I). Oakland, CA: The Wing Institute.

Division 16 of the American Psychological Association and Society for the Study of School Psychology Task Force on Evidence-Based Interventions in School Psychology. (2003). Procedural and coding manual for review of evidence-based interventions. Washington, DC: American Psychological Association.

Fuchs, D., Fuchs, L. S., Thompson, A., Svenson, E., Yen, L., Al Otaiba, S., ... Saenz, L. (2001). Peerassisted learning strategies in reading: Extensions for kindergarten, first grade, and high school. Remedial and Special Education, 22, 15-21. doi:10.1177/074193250102200103

Gersten, R., Fuchs, L. S., Compton, D., Coyne, M., Greenwood, C., \& Innocenti, M. S. (2005). Quality indicators for group experimental and quasi-experimental research in special education. Exceptional Children, 71, 149-164. doi: 10.1177/001440290507100202 
Gilroy, A., \& Moore, D. W. (1988). Reciprocal teaching of comprehension-fostering and comprehension-monitoring activities with ten primary school girls. Educational Psychology, 8, 41-49. doi:10.1080/0144341880080105

Gunning, T. G. (2016). Creating literacy instruction for all children (9th ed.). Boston, MA: Pearson.

Han, J., \& Neuharth-Pritchett, S. (2015). Meaning-related and print-related interactions between preschoolers and parents during shared book reading and their associations with emergent literacy skills. Journal of Research in Childhood Education, 29, 528-550. doi:10.1080/02568543.2015.1073819

Holdaway, D. (1979). The foundations of literacy. Toronto, Canada: Ashton Scholastic.

Huang, C.-T., \& Yang, S. C. (2015). Effects of online reciprocal teaching on reading strategies, comprehension, self-efficacy, and motivation. Journal of Educational Computing Research, 52, 381-407. doi:10.1177/0735633115571924

Institute of Education Sciences (IES) and National Science Foundation (NSF). (2013). Common guidelines for education research and development. Washington, DC: Authors.

Justice, L. M., McGinty, A. S., Piasta, S. B., Kaderavek, J. N., \& Fan, X. (2010). Print-focused readalouds in preschool classrooms: Intervention effectiveness and moderators of child outcomes. Language, Speech, and Hearing Services in Schools, 41, 504-520. doi:10.1044/01611461(2010/09-0056

Kazdin, A. E. (2011). Single-case research design: Methods for clinical and applied settings (2nd ed.). New York, NY: Oxford University Press.

Kelly, M., Moore, D. W., \& Tuck, B. F. (1994). Reciprocal teaching in a regular primary school classroom. Journal of Educational Research, 88, 53-61. doi:10.1080/00220671.1994.9944834

Klingner, J. K., \& Vaughn, S. (1996). Reciprocal teaching of reading comprehension strategies for students with learning disabilities who use English as a second language. The Elementary School Journal, 96, 275-293. doi:10.1086/461828

Lysynchuk, L. M., Pressley, M., \& Vye, N. J. (1990). Reciprocal teaching improves standardized reading-comprehension performance in poor comprehenders. The Elementary School Journal, 90, 469-484. doi:10.1086/461627

Malouf, D. B., \& Taymans, J. M. (2016). Anatomy of an evidence base. Educational Researcher, 45, 454-459. doi:10.3102/0013189X16678417

Mandel, E., Osana, H. P., \& Venkatesh, V. (2013). Addressing the effects of reciprocal teaching on the receptive and expressive vocabulary of 1st-grade students. Journal of Research in Childhood Education, 27, 407-426. doi:10.1080/02568543.2013.824526

Marks, M., Pressley, M., Coley, J. D., Craig, S., Gardner, R., DePinto, W., \& Rose, W. (1993). Three teachers' adaptations of reciprocal teaching in comparison to traditional reciprocal teaching. The Elementary School Journal, 94, 267-283. doi:10.1086/461766

Marston, D., Deno, S. L., Kim, D., Diment, K., \& Rogers, D. (1995). Comparison of reading intervention approaches for students with mild disabilities. Exceptional Children, 62, 20-37. doi:10.1177/001440299506200103

Palincsar, A. S., \& Brown, A. L. (1984). Reciprocal teaching of comprehension-fostering and comprehension-monitoring activities. Cognition and Instruction, 2, 117-175. doi:10.1207/s1532690xci0102_1

Palincsar, A. S., \& Brown, A. L. (1986). Interactive teaching to promote independent learning from text. The Reading Teacher, 39, 771-777. 
Palincsar, A. S., \& Brown, A. L. (1988). Teaching and practicing thinking skills to promote comprehension in the context of group problem solving. Remedial and Special Education, 9, 53-59. doi:10.1177/074193258800900110

Piasta, S. B., Justice, L. M., McGinty, A. S., \& Kaderavek, J. N. (2012). Increasing young children's contact with print during shared reading: Longitudinal effects on literacy achievement. Child Development, 83, 810-820. doi:10.1111/j.1467-8624.2012.01754.x

Pollard-Durodola, S. D., Gonzalez, J. E., Simmons, D. C., Kwok, O., Taylor, A. B., Davis, M. J., ... Simmons, L. (2011). The effects of an intensive shared book-reading intervention for preschool children at risk for vocabulary delay. Exceptional Children, 77, 161-183. doi:10.1177/001440291107700202

Reutzel, D. R., \& Cooter, R. B. (2016). Teaching children to read: The teacher makes the difference (7th ed.). Boston, MA: Pearson.

Schirmer, B. R., \& Williams, C. (2008). Evidence-based practices are not reformulated best practices. Communication Disorders Quarterly, 29, 166-168. doi:10.1177/1525740108320354

U.S. Department of Education, Institute of Education Sciences (IES), What Works Clearinghouse (WWC). (2013, November). Students with learning disabilities intervention report: Reciprocal teaching. Retrieved from https://ies.ed.gov/ncee/wwc/Docs/InterventionReports/wwc_reciprocalteaching_112613.pdf

U.S. Department of Education, Institute of Education Sciences (IES), What Works Clearinghouse (WWC). (2015, April). Early childhood education intervention report: Shared book reading. Retrieved from https://ies.ed.gov/ncee/wwc/Docs/InterventionReports/wwc_sharedbook_041415.pdf

Vacca, J. L., Vacca, R. T., Gove, M. K., Burkey, L. C., Lenhart, L. A., \& McKeon, C. A. (2015). Reading and learning to read (9th ed.). Boston, MA: Pearson.

Vygotsky, L. S. (1978). Mind in society: The development of higher psychological processes. Cambridge, MA: Harvard University.

Westera, J., \& Moore, D. W. (1995). Reciprocal teaching of reading comprehension in a New Zealand high school. Psychology in the Schools, 32, 225-232. doi:10.1002/1520-6807(199507)32:3<225

What Works Clearinghouse (WWC). (2017). Procedures and standards handbook version 4.0. Retrieved from https://ies.ed.gov/ncee/wwc/handbooks

What Works Clearinghouse (WWC). (n.d.). Intervention reports and educators practice guides. Retrieved at https://ies.ed.gov/ncee/wwc/Publication\#/ContentTypeId:1 
The Journal of Educational Research and Practice provides a forum for studies and dialogue that allows readers to better develop social change in the field of education and learning. Journal content may focus on educational issues of all ages and in all settings. It also presents peer-reviewed commentaries, book reviews, interviews of prominent individuals, and additional content. The objectives: We publish research and related content that examines current relevant educational issues and processes aimed at presenting readers with knowledge and showing how that knowledge can be used to impact social change in educational or learning environments. Additional content provides an opportunity for scholarly and professional dialogue regarding that content's usefulness in expanding the body of scholarly knowledge and increasing readers' effectiveness as educators. The journal also focuses on facilitating the activities of both researcher-practitioners and practitioner-researchers, providing optimal opportunities for interdisciplinary and collaborative thought through blogging and other communications.

Walden University Publishing: http://www.publishing.waldenu.edu 